\title{
Masked repetition and phonological priming in picture naming
}

\author{
LUDOVIC FERRAND \\ CNRS and Université René Descartes, Paris, France \\ and University of Birmingham, Birmingham, England \\ GLYN W. HUMPHREYS \\ University of Birmingham, Birmingham, England \\ and \\ JUAN SEGUI \\ CNRS and Université René Descartes, Paris, France
}

\begin{abstract}
We report a series of picture naming experiments in which target pictures were primed by briefly presented masked words. Experiment 1 demonstrates that the prior presentation of the same word prime (e.g., rose-ROSE) facilitates picture naming independently of the target's name frequency. In Experiment 2, primes that were homophones of picture targets (e.g., rows-ROSE) also produced facilitatory effects compared with unrelated controls, but priming was significantly larger for targets with low-frequency names relative to targets with high-frequency names. In Experiment 3, primes that were higher frequency homophones of picture targets produced facilitatory effects compared with identical primes. These results are discussed in relation to different accounts of the effects of masked priming in current models of picture naming.
\end{abstract}

Articulating the name that corresponds to the picture of a common object is a fast, efficient, and relatively effortless cognitive skill. These aspects of performance obscure the complexity of the processes involved, and experimental psychologists must therefore devise methods to remove this obscurity (see, e.g., Ferrand, 1997; Glaser, 1992; Johnson, Paivio, \& Clark, 1996; Riddoch \& Humphreys, 1987). This has led to the elaboration of various new techniques, such as masked or unmasked priming (Durso \& Johnson, 1979; Ferrand, Grainger, \& Segui, 1994), picture-word interference (Glaser, 1992), picture-naming-to-deadline (Vitkovitch \& Humphreys, 1991; Vitkovitch, Humphreys, \& Lloyd-Jones, 1993), and postcue naming (Humphreys, Lloyd-Jones, \& Fias, 1995), to study the representations and processes involved in picture naming. In the present article, we examine the effects of repetition and phonological priming in picture naming.

\section{Picture-Word Interference Studies}

A number of picture-word interference studies have focused on the effects of the phonological characteristics of

The research reported in this article was partially supported by a postdoctoral grant (COGNISCIENCES) to L.F. from the Centre National de la Recherche Scientifique (CNRS) and by an Economic and Social Research Council grant to G.H. The authors thank Joanne Miller, Ken Forster, Guy Van Orden, and two anonymous reviewers for helpful comments on this work. Correspondence should be addressed to L. Ferrand, Laboratoire de Psychologie Expérimentale, CNRS, and Université René Descartes, 28 rue Serpente, 75006 Paris, France (e-mail: ferrandl@, idf.ext.jussieu.fr). interfering words on picture naming (Lupker, 1982; Meyer \& Schriefers, 1991; Rayner \& Posnansky, 1978; Schriefers, Meyer, \& Levelt, 1990; Starreveld \& La Heij, 1995; Underwood \& Briggs, 1984). The results of these studies suggest that phonologically similar word (or nonword) distractors decrease the interference effect relative to unrelated distractors. In particular, Rayner and Posnansky presented pictures with a nonword superimposed in the middle; the visual and phonological similarity of the nonword to the actual picture name was varied. Nonwords that were phonologically related to the target picture name (e.g., the pseudohomophone burd for the target picture BIRD) produced faster naming latencies than did unrelated nonwords. Lupker also reported a significant phonological facilitation effect for rhyming pairs (such as ROSE-NOSE). However, Underwood and Briggs failed to replicate this effect: The picture of a LEAF (for instance) was not named faster when accompanied by the phonologically related distractor word thief than when accompanied by the unrelated distractor word dirt. In a more recent study, Schriefers et al. (1990), using a paradigm in which the distractor words were presented auditorily, found that phonologically related words (e.g., fog when the target picture was DOG) facilitated picture naming latencies more than did unrelated words (e.g., roof when the picture target was DOG; see also Meyer \& Schriefers, 1991). This phonological facilitation effect is generally assumed to be localized at the name retrieval level (see Lupker, 1982, and Schriefers et al., 1990). At the lexical level, a distractor word will activate all word nodes that are phonologically similar with it. Therefore, a distractor word that is phonologically related to the tar- 
get picture's name will also facilitate the word node of the depicted object to some extent. Retrieval of the target name is then easier than when an unrelated distractor is presented.

\section{Priming Studies}

Recent priming studies (Bajo \& Canas, 1989; Collins \& Ellis, 1992; Lupker \& Williams, 1989; McEvoy, 1988; Wheeldon \& Monsell, 1992) have also reported that phonologically similar word or nonword primes facilitate picture naming in conditions in which primes are clearly visible or audible. For instance, Collins and Ellis, using a paradigm in which subjects repeated aloud auditorily presented primes and then named picture targets, reported that target pictures were named faster when prime and target shared phonemes in the same position (e.g., dock-DUCK). They also showed that the size of this phonological priming effect was very similar for word and nonword primes. Using the postcue picture naming procedure, in which subjects name one of two potential target stimuli after they receive a relevant selection cue, Lloyd-Jones and Humphreys (1995) have recently shown facilitation for phonologically related pairs (e.g., distractor picture ANCHOR, target picture ANT). All these results converge to suggest that picture naming can be speeded up by the prior presentation of a phonologically related stimulus.

\section{Masked Priming in Picture Naming}

Studies of priming under masking conditions can be used to evaluate the operations that are engaged automatically in stimulus processing, since priming can occur even when primes cannot be reported overtly. Ferrand et al. (1994) reported a series of picture naming experiments using the masked priming paradigm with prime exposures brief enough to prevent identification. They found chancelevel performance when subjects were asked to judge whether or not the masked prime word was nominally the same as the picture target, suggesting that very little precise information about the prime's identity was available for conscious identification. This absence of awareness was taken as clear evidence for the automaticity of the processes under study. However, even in such impoverished prime presentation conditions, there was evidence that high-level (e.g., lexical) representations were activated during prime processing and subsequently affected picture naming. Using this masked priming technique, Ferrand et al. also examined the types of codes that are generated under masking conditions when prime stimuli are words or pronounceable string of letters. They demonstrated that the prior presentation of the same word prime facilitated picture naming independently of the frequency of the target picture's name. Furthermore, similar effects were obtained using primes that were pseudohomophones of the picture targets (e.g., peech-PEACH). Interestingly, picture naming was facilitated by the prior masked visual presentation of the same phonological word form relative to baselines with both unrelated and orthographically related primes (e.g., roune-PEACH, peath-PEACH). However, masked orthographic primes failed to facilitate picture naming relative to unrelated controls. More recently, Ferrand (1995) extended these results using (1) a new set of picture stimuli including digit numbers and (2) repeated prime-target stimuli. Ferrand showed that phonological priming from pseudohomophone primes was similar in size to the repetition effect from identical primes. Pseudohomophone priming also remained robust even after the subjects had become very familiar with the stimuli, suggesting that it reflects highly automatized and mandatory processing of prime stimuli. The results obtained by Ferrand et al. have been recently replicated by Xing and Forster (1996) with the same masked priming technique in English. Given that these results were observed in conditions that prevent conscious identification (briefly presented forward and backward masked primes), they are consistent with recent evidence showing that phonological information about a written word becomes available rapidly and automatically (see Berent \& Perfetti, 1995; Ferrand \& Grainger, 1992, 1993, 1994, 1996; Grainger \& Ferrand, 1994, 1996; Lukatela \& Turvey, 1994; Perfetti \& Bell, 1991; Ziegler \& Jacobs, 1995).

In order to capture these results, Ferrand et al. (1994) presented a simple activation model of picture (and word) naming (see their Figure 8). This model introduces a distinction between an orthographic and a phonological lexicon and between sublexical orthographic units and sublexical phonological units (see also Ferrand, Segui, \& Grainger, 1996). Sublexical orthographic units are activated by printed words and these in turn activate in parallel both orthographic and phonological word units. In contrast, picture representations only send activation directly to the phonological lexicon. The final articulatory output is assumed to depend both on the activity of wholeword units and sublexical orthographic/phonological units. Due to the hypothetical time course of information flow in this model (determined by its architecture), when a picture is being named, the articulatory output will receive activation first from whole-word phonological representations. Thus, picture naming will be mainly influenced by activity in the phonological lexicon. A briefly presented pseudohomophone or word prime can affect picture naming by activating the corresponding phonological word unit in memory, thus giving rise to facilitation in picture naming. Since the same word unit is activated by both primes, performance is facilitated to the same extent by pseudohomophones and repeated words alike.

\section{The Present Study}

One possible problem in Ferrand et al.'s (1994) interpretation of their data lies in the fact that they compared repeated word primes with pseudohomophonic nonword primes. An alternative interpretation of their results would be that the pseudohomophone primes activated the semantic representation of the corresponding picture name, suggesting that both semantic and phonological properties of this picture name contribute to the repetition priming effect (see Wheeldon \& Monsell, 1992, for instance). 


\section{IDENTICAL}

(word "rose" / picture "rose")

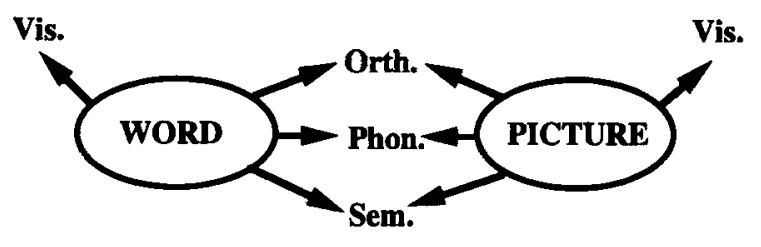

HOMOPHONE

(homophone "rows" / picture "rose")

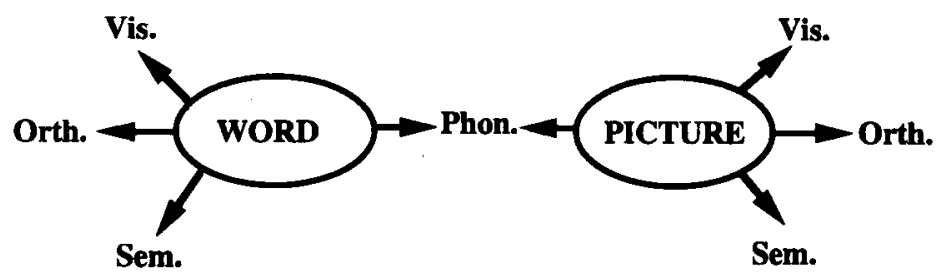

Figure 1. Schematic representation of the two kinds of similarity studied (adapted from Bavelier, 1994). Codes written in between the two targets are common to these targets; the other codes are different. Vis., visual code; Orth., orthographic code; Phon., phonological code; Sem., semantic code.

A pilot study recently conducted by Ferrand, Segui, and Grainger (1995) demonstrated that when the prime was a homophone of a picture target (e.g., rows for the picture of a ROSE) facilitation effects measured relative to unrelated prime words were practically the same size as when primes were nominally identical to the target (e.g., rose for the picture of a ROSE). However, the frequency of the target picture names was not manipulated in this study. There are grounds for arguing that picture name frequency effects reflect the process of phonological name retrieval (Jescheniak \& Levelt, 1994; Morrison, Ellis, \& Quinlan, 1992; Riddoch \& Humphreys, 1987; Wingfield, 1968; for a review see Johnson et al., 1996). By manipulating effects of name frequency as well as phonological relatedness between primes and targets, we provide an experimental handle on the locus of the phonological priming effect on picture naming. In order to test the alternative outlined above, the present experiments used identical word primes as well as homophone word primes crossed with target frequency in a masked picture priming paradigm. Note that these homophone primes are unrelated in meaning to the corresponding picture targets. In Figure 1 we present a schematic representation of the two kinds of similarity studied that will serve to clarify the predictions that can be made. What is critical in these two kinds of similarity, with respect to whether primes will affect picture naming responses, is that whereas identical primes shared in common all the dimensions (apart from the visual dimension), homophone primes were semantically and orthographically different from words corresponding to the picture names and shared only the phonological dimension. If the repetition priming effect is indeed uniquely based on phonological representations, one should observe equivalent facilitation in picture naming latencies independently of whether the prime is the same word as the target (e.g., rose) or is a homophone of the target (e.g., rows). On the other hand, if semantic representations play a role in the repetition effect, then, since homophonic word primes are unrelated in meaning, they should produce less facilitation in picture naming.

According to Humphreys et al. (Humphreys, Lamote, \& Lloyd-Jones, 1995; Humphreys, Lloyd-Jones, \& Fias, 1995; Humphreys, Riddoch, \& Quinlan, 1988), picture naming is accomplished by a sequence of at least four processes - namely activation of stored structural knowledge about the object's appearance, activation of semantic information, name retrieval, and articulation. More than one of these stages could be affected by the masked prime, and the different properties of the prime could affect different stages. According to Xing and Forster (1996), there are three possible sites at which an identical prime could affect the naming of target pictures. For instance, if we have a picture of a ROSE primed with the word rose, priming could speed up the process of activating the semantic representation necessary for retrieving the picture name, since this representation itself may have already been activated by the prime. This possibility (priming at the level of semantic representation) is ruled out or at least reduced here by the use of homophone primes (which have no semantic information in common with the target). A 
second possibility is that the prime speeds up the process of name retrieval, if we assume that the lexical representation required for naming the object is the same as the representation activated by the prime. Finally, the prime could facilitate the process of articulation itself. That activation of a name representation, rather than articulation per se, is the priming locus is suggested by (1) equivalent amounts of facilitation following covert and overt naming practice (see Brown, Neblett, Jones, \& Mitchell, 1991, and Johnson et al., 1996), and (2) evidence of priming from word reading tasks that did not involve overt production (Ferrand, 1994; Ferrand et al., 1995).

In the following experiments, the targets were always line drawings of common objects. The subject's task was to name the pictures as quickly as possible. Naming latencies were the main dependent variable. The experimental conditions differed with respect to the type of relationship between the prime and the target. In Experiment 1, primes and targets were either repeated or unrelated. In Experiment 2, primes and targets were either homophones or unrelated. In Experiment 3, primes were either homophones of higher frequency or identical to targets. These experiments also examined the priming effects for high- and low-frequency picture names.

\section{EXPERIMENT 1}

\section{Method}

Subjects. Sixteen students at the University of Birmingham, England, served as subjects for a small payment. All were native speakers of English, with normal or corrected-to-normal vision.

Stimuli and Design. Thirty-six simple black-on-white line drawings of common objects served as experimental pictures. In addition, there were 10 practice pictures. Most of the drawings were selected from the norms of Snodgrass and Vanderwart (1980) and were digitized (using a HP-Scan Jet IIc). Half had high-frequency names (with an average of 75 occurrences per million, ranging from a minimum of 13 to a maximum of 173; Francis \& Kučera, 1982), and the remaining half had low printed frequency (with an average of $3 \mathrm{oc}-$ currences per million, ranging from a minimum of 0 to a maximum of 9). For each target picture, two types of word primes were selected: (1) word primes that were identical to the target picture name (e.g., rose-ROSE) and (2) word primes that were unrelated ${ }^{1}$ to the target picture name (e.g., taxi-ROSE). Each unrelated prime was a word that was of the same length (i.e., the same number of letters) of the corresponding target. Priming condition was crossed with target frequency in a $2 \times 2$ factorial design. Prime-target pairs were counterbalanced across the priming conditions across two groups of subjects so that none of the subjects saw any single prime or target picture more than once, but each subject received all four experimental conditions. Every subject saw 36 word-prime/picture-target pairs, 9 from each condition. For word primes, each character covered approximately $0.38^{\circ}$ of visual angle from a viewing distance of $60 \mathrm{~cm}$, whereas for picture targets, the mean angular size of the stimuli was $2.5^{\circ}$ horizontally and vertically (ranging from $1.8^{\circ}$ to $3^{\circ}$ ). A complete list of the verbal stimuli is presented in Appendix A.

Procedure. The subjects were tested individually. Before the experiment proper was started, the subjects were given a booklet containing all the drawings (following Ferrand et al., 1994). Next to each object was printed the word that the subjects in Snodgrass and Vanderwart (1980) had used spontaneously most frequently to name the depicted object. The subjects were asked to examine all the drawings, to study their names, and to use only those names to refer to the pictures in the experiment. Word primes and target pictures were presented in the center of the screen of a personal computer with a $70-\mathrm{Hz}$ refresh rate. They appeared as black on a white background. The masked prime procedure with the picture naming task used in the experiments of Ferrand et al. was adopted here. Each trial consisted of the following sequence of four stimuli. First a forward pattern mask was presented for $500 \mathrm{msec}$. This was immediately followed by presentation of the prime word for $29 \mathrm{msec}$, which was followed immediately by a backward pattern mask for $14 \mathrm{msec}$. This was immediately followed by presentation of the target picture in the same screen location as the masks. The target pictures remained on the screen until the subjects responded. Word primes were always presented in uppercase letters. The subjects were asked to fixate the middle of the forward mask and to name the depicted object as rapidly and as accurately as possible. The existence of a word prime was not mentioned. The computer recorded the naming times from target onset to the triggering of the voice key by the subject's response. The experimenter sat in the same room as the subject in order to check and note the responses. The next trial sequence followed after a 3-sec delay. Stimulus presentation was randomized, with a different order for each subject. The estimated visibility of the primes was tested in earlier closely related experiments (Ferrand et al., 1994). The subject's task was to decide whether the prime was nominally the same as the picture target; in other words, subjects performed a forcedchoice same-different judgment. The overall percent correct rate was $49 \%$. Moreover, the overall percent correct value was almost identical for high-frequency and low-frequency targets. This absence of a frequency effect provides further evidence that the subjects had very little information available from the prime stimuli. Therefore, it seems safe to conclude that very little precise information about the prime as a whole was available for conscious identification.

\section{Results}

Trials on which subjects incorrectly named pictures, repeated their utterances, or stuttered were regarded as errors. Mean naming latencies and percentage of errors are given in Figure 2. Latencies longer than $1,500 \mathrm{msec}$ were excluded (less than $2 \%$ of the data). Priming condition (identical prime and unrelated prime) and target frequency were entered as main factors in an analysis of variance (ANOVA) of the data for the picture targets. $F$ values are reported by subjects $\left(F_{1}\right)$ and by items $\left(F_{2}\right)$.

There was a significant main effect of priming condition [+40 msec; $F_{1}(1,14)=73.35, p<.001$, and $F_{2}(1,34)=$ $40.39, p<.001]$. There was also a main effect of target frequency $\left[+62 \mathrm{msec} ; F_{1}(1,14)=26.84, p<.001\right.$, and $\left.F_{2}(1,34)=37.36, p<.001\right]$. The interaction between priming condition and target frequency was not significant (all $F \mathrm{~s}<1)$. An ANOVA performed on the error data showed no main or interaction effects (all $F \mathrm{~s}<1$ ).

\section{Discussion}

The results of Experiment 1 clearly replicate the results obtained by Ferrand et al. (1994) showing that the naming of pictures is facilitated by masked identical word primes (relative to unrelated controls). ${ }^{2}$ According to activationbased models of picture naming (Ferrand et al., 1994; Humphreys, Lamote, \& Lloyd-Jones, 1995; Humphreys, Lloyd-Jones, \& Fias, 1995; Humphreys, Riddoch, \& Quinlan, 1988), masked repetition priming can be explained by the preactivation of the target's phonological lexical representation by the prime stimulus. This can also be applied 


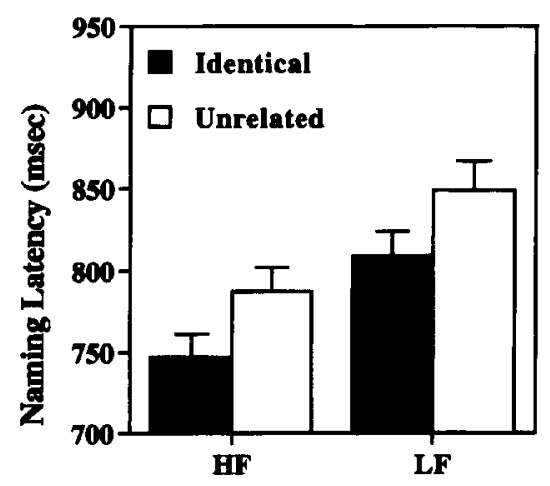

Target Frequency

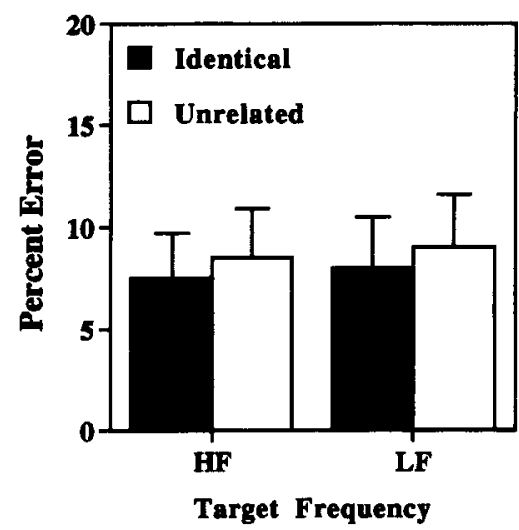

Figure 2. Mean naming latencies (in milliseconds) and percent errors in Experiment 1 (picture naming) as a function of type of prime-target relation (repeated vs. unrelated) and target frequency. Vertical bars represent standard errors. HF, high frequency; LF, low frequency.

to activation-based models of speech production (Dell, 1988; Stemberger, 1985). In Forster's model of word processing, the priming effect can be attributed to the masked prime opening the entry for the target in a central master lexicon (Forster \& Davis, 1984). Interestingly, low- and highfrequency picture targets here produced comparable repetition effects, thus replicating prior observations of additive relations between masked repetition priming and target frequency in tasks such as word naming (Ferrand, 1996; Sereno, 1991), picture naming (Ferrand et al., 1994), lexical decision (Forster \& Davis, 1984; Segui \& Grainger, 1990; Sereno, 1991), and perceptual identification (Humphreys, Besner, \& Quinlan, 1988).

In addition to the reliable repetition effect, there was also an effect of name frequency (see also Ferrand et al., 1994; Ferrand et al., 1995; Humphreys, Riddoch, \& Quinlan, 1988; Huttenlocher \& Kubicek, 1983; Jescheniak \& Levelt, 1994; Oldfield \& Wingfield, 1965). Moreover, Wingfield (1968) and Jescheniak and Levelt have shown that the frequency effect is not due to the time needed to recognize the object, but reflects differences in name retrieval. Various attempts to account for frequency effects have been offered. Within the framework of the interactive activation model of speech production developed by Stem- berger (1985), entries in the lexicon that are frequently activated develop higher resting levels of activation than entries that are less frequently activated (see McClelland \& Rumelhart, 1981). High-frequency names therefore attain the critical levels of activation necessary for generating an articulatory response more rapidly than names that are less frequently activated (see also Dell, 1988). Within the framework of the cascade model of picture naming developed by Humphreys et al. (Humphreys, Lamote, \& LloydJones, 1995; Humphreys, Riddoch, \& Quinlan, 1988; see also Ferrand et al., 1994), name frequency is also assumed to affect access to phonological representations. Within the framework of the two-stage model of speech production developed by Jescheniak and Levelt (1994), this frequency effect arises in accessing the phonological form but not in accessing the syntactic word (the lemma) of the corresponding picture name.

The fact that low- and high-frequency picture targets produced comparable repetition priming effects can be explained in several ways. Most theorists would argue that activation-based models would predict less priming for high-frequency names, since their resting levels are much closer to the criterion value. Under masking conditions, one has to postulate that the increase in activation is of the same magnitude regardless of frequency to account for the additive effects of repetition and frequency (or the important factor could be the relative prime-target frequency; see Experiment 3 and Grainger \& Ferrand, 1994). It is worth noting that this absence of an interaction in word priming studies (subsequently confirmed by at least two independent studies) led Forster and Davis (1984) to postulate that priming did not alter the accessibility of the target word. In Forster and Davis's discrete processing account, priming occurs as a result of a change in the state of the lexical entry that is manifested once the entry is accessed, not as a result of a change in the accessibility of the entry, since otherwise priming should interact with a variable such as frequency, which also affects accessibility. Another possibility is that name frequency influences the links between semantic and phonological name representations, but not the phonological representations themselves (McCann \& Besner, 1987). Preactivation of the phonological representations (from priming) may then combine additively with effects altering the speed of mapping between semantic and name representations (i.e., name frequency).

We return to reconsider such accounts after Experiment 2 . The main aim of Experiment 2 was to assess whether the repetition effect observed in Experiment 1 was due to primes preactivating target pictures at a semantic or name level of representation. To assess this, Experiment 2 examined priming from stimuli that were homophones of the target picture names. Since these homophones were semantically and orthographically different from words corresponding to the picture names (see Figure 1), priming should not occur at a semantic level or from sublexical orthographic representations activated by primes. If priming is not found between words and pictures that share only similar phonological representations (in contrast to the repetition priming effect observed in Experi- 


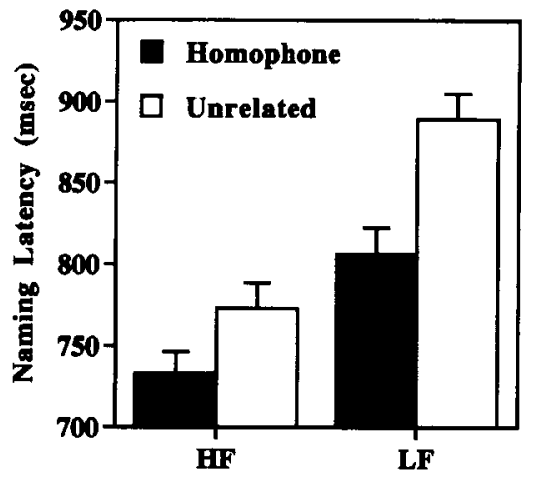

Target Frequency

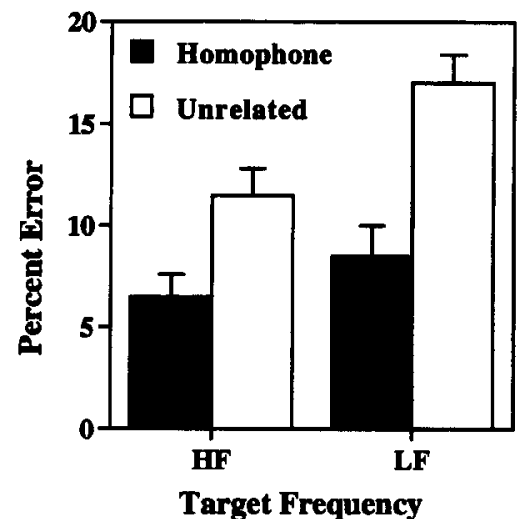

Figure 3. Mean naming latencies (in milliseconds) and percent errors in Experiment 2 (picture naming) as a function of type of prime-target relation (homophone vs. unrelated) and target frequency. Vertical bars represent standard errors. HF, high frequency; LF, low frequency.

ment 1 between words and pictures that share identical semantic and phonological representations), it is likely that cross-modal repetition priming (from word to picture) is determined only by semantic similarity. However, if priming is found between a written homophone and its picture, it is likely that at least part of repetition priming between words and pictures is phonologically based.

\section{EXPERIMENT 2}

After establishing that a cross-modal repetition priming effect (from word to picture) exists (see also Ferrand, 1995; Ferrand et al., 1994; Ferrand et al., 1995; Xing \& Forster, 1996), the next step is to consider what might happen if the prime is a homophone of the same target picture names as those used in Experiment 1. Due to the architecture of Ferrand et al.'s (1994) model, homophone primes should activate the same phonological representation as an identity prime, and these primes should produce equally large priming effects.

\section{Method}

Subjects. Twenty students at the University of Birmingham, England, served as subjects for a small payment. All were native speak- ers of English, with normal or corrected-to-normal vision. None of these subjects had participated in the previous experiment.

Stimuli and Design. The design and the target pictures were exactly the same as in Experiment 1, except that the identical word primes from Experiment 1 were replaced by homophone primes (real words). For each target picture, two types of word prime were selected: (1) word primes that were homophonic but orthographically dissimilar to the target picture name (e.g., rows-ROSE) and (2) word primes that were unrelated to the target picture name (e.g., taxi-ROSE). Priming condition was crossed with target frequency in a $2 \times 2$ factorial design. A complete list of the verbal stimuli is presented in Appendix B.

Procedure. The procedure was the same as in Experiment 1.

\section{Results}

Mean naming latencies and percentage of errors are given in Figure 3. Latencies longer than $1,500 \mathrm{msec}$ were excluded (less than $5 \%$ of the data). Priming condition (homophone prime and unrelated prime) and target frequency were entered as main factors in an ANOVA of the data of the picture targets. $F$ values are reported by subjects $\left(F_{1}\right)$ and by items $\left(F_{2}\right)$.

There was a significant main effect of priming condition $\left[+61 \mathrm{msec} ; F_{1}(1,18)=39.15, p<.001\right.$, and $F_{2}(1,34)=$ $67.58, p<.01]$. There was also a main effect of target frequency $\left[+94 \mathrm{msec} ; F_{1}(1,18)=75.66, p<.001\right.$, and $\left.F_{2}(1,34)=73.09, p<.001\right]$. In contrast to Experiment 1 , the interaction between priming condition and target frequency was significant $\left[F_{1}(1,18)=8.15, p<.01\right.$, and $\left.F_{2}(1,34)=11.33, p<.005\right]$. The priming effect was stronger for low- than for high-frequency targets $(+83 \mathrm{msec}$ vs. $+40 \mathrm{msec}$ ). The error data showed the same pattern of effects as the response time (RT) data did. An ANOVA performed on these error data showed a significant effect of priming condition $\left[+8 \% ; F_{1}(1,18)=17.04, p<.001\right.$, and $\left.F_{2}(1,34)=27.59, p<.001\right]$. The effect of target frequency was also significant $\left[+3 \% ; F_{1}(1,18)=7.64, p<.02\right.$, and $\left.F_{2}(1,34)=4.46, p<.05\right]$. However, the priming condition $\times$ target frequency interaction was only marginally significant $\left[F_{1}(1,18)=3.91, p=.063\right.$, and $F_{2}(1,34)=3.57$, $p=.067]$.

\section{Discussion}

The results of Experiment 2 clearly show that picture naming is strongly and reliably facilitated by the prior presentation of masked homophone primes that are orthographically and semantically dissimilar from the targets (e.g., rows-ROSE). The fact that picture naming was facilitated by the prior masked presentation of a homophone of the picture name suggests that the brief presentation $(29 \mathrm{msec})$ of a written word is sufficient to activate phonological lexical representations that are involved in naming picture targets. The cross-modal repetition effect observed in Experiment 1 (from word to picture) could be due to (1) the prior activation of the same meaning, (2) the prior activation of the same phonological representation, or (3) the prior activation of both the same meaning and the same phonological representation. Experiment 2 was designed to test these possibilities. Importantly, the results of Experiment 2 allow us to reject an interpretation of the fa- 
cilitatory effects of repeated primes and pseudohomophone primes observed in Experiment 1 and by Ferrand et al. (1994) in terms of semantic activation alone, since the homophone primes used in Experiment 2 were semantically unrelated to the picture targets. Rather, these results show that phonological identity alone is sufficient to produce a sizable amount of priming. These results also go against an interpretation of the priming effects in terms of partial phonological overlap created by orthographic structures in primes, since the homophone primes were orthographically dissimilar to words corresponding to the picture targets in Experiment 2. As already noted in the introduction, masked orthographic primes failed to facilitate picture naming relative to unrelated controls (Ferrand et al., 1994). The present results therefore add further support to the conclusions drawn by Ferrand et al. Using the same paradigm, these authors reported that picture naming was facilitated by the prior masked presentation of the same phonological form, independently of whether primes were nominally identical to the target (e.g., rose-ROSE) or were pseudohomophones of the target name (e.g., rozeROSE). Taken together, the results strongly suggest that the representation underlying the masked repetition effect in picture naming is a whole-word phonological representation. Such a representation may be equally strongly activated by the corresponding word, a homophone of that word, or a pseudohomophone of that word.

In contrast to Experiment 1, here there was a clear interaction between (homophone) priming and target name frequency: Priming was about twice as large for targets with low-frequency names relative to those with high-frequency names.

A closer examination of the relative frequencies of the prime-target pairs in Experiment 2 indicates that for lowfrequency targets, primes had higher frequencies (the average frequency for targets was 3 occurrences per million, whereas for primes it was 40 occurrences per million). This difference could underlie the frequency $\times$ priming interaction. On an interactive activation account, the increase in priming in the homophone condition for low-frequency target names (relative to high-frequency target names) could be attributed to the different frequencies of the primes. For example, high-frequency primes (with low-frequency targets) could generate stronger phonological activation than low-frequency primes (with high-frequency targets), leading to stronger priming for low-frequency targets. This hypothesis was tested in Experiment 3, in which we primed low-frequency targets by either higher frequency homophone primes or by identical primes.

\section{EXPERIMENT 3}

\footnotetext{
Method

Subjects. Twenty additional students at the University of Birmingham, England, served as subjects for a small payment. All were native speakers of English, with normal or corrected-to-normal vision. None of these subjects had participated in the previous experiments.

Stimuli and Design. Eighteen low-frequency target pictures taken from Experiment 2 served as experimental pictures. Two types
}

of word prime were selected: (1) word primes that were homophonic but more frequent than the target picture name and (2) word primes that were identical to the target picture name. As in Experiment 2, the average frequency of the target was 3 occurrences per million and 40 occurrences per million for the homophonic primes. Prime-target pairs were counterbalanced across the priming conditions across two groups of subjects so that none of the subjects saw any single prime or target picture more than once, but each subject received the two experimental conditions. Every subject saw 18 word-prime/picturetarget pairs, 9 from each condition. A list of stimuli is presented in Appendix B.

Procedure. The procedure was the same as in Experiment 1.

\section{Results}

Mean naming latencies are given in Figure 4. Latencies longer than $1,500 \mathrm{msec}$ were excluded (less than $5 \%$ of the data). Priming condition (homophone prime of higher frequency and identical prime) was entered as main factor in an ANOVA of the data of the picture targets. $F$ values are reported by subjects $\left(F_{1}\right)$ and by items $\left(F_{2}\right)$.

There was a significant effect of priming condition $\left[F_{1}(1,18)=6.89, p<.02\right.$, and $\left.F_{2}(1,17)=4.47, p<.05\right]$, with homophone primes of higher frequency leading to faster picture naming latencies than identical primes $(+33 \mathrm{msec})$. An ANOVA performed on the error data showed no significant effect $\left[F_{1}(1,18)=2.51\right.$, and $\left.F_{2}(1,17)=2.83\right]$.

\section{Discussion}

The results of Experiment 3 clearly show that picture naming is reliably facilitated by prior presentation of masked homophone primes that are of higher frequency than the name of the target itself. More importantly, increasing the frequency of a homophone prime produces a marked change in the pattern of effects. When homophonic primes are more frequent than targets, they facilitate even more than identical primes (with overlapping semantic as well as phonological representations).

Our finding that homophone primes facilitate naming more than identical primes reiterates that the present priming effects are phonological rather than semantic in nature. The results also support the proposal that the magnitude of phonological priming on low-frequency targets is a function of the frequency of the prime. Here, high-frequency primes (in the homophone condition) produced stronger priming than did low-frequency primes (in the same-identity condition) even though the low-frequency primes alone shared semantic representations with target pictures.

\section{GENERAL DISCUSSION}

The results of the present cross-modal experiments (from word to picture) may be summarized as follows. Experiment 1 demonstrates that the prior presentation of the same word prime facilitates picture naming independently of the target's name frequency (i.e., repetition priming and frequency are additive). In Experiment 2, primes that were homophones of picture targets (e.g., rows-ROSE) produced facilitatory effects compared with unrelated controls, but the priming effect was significantly larger for lowfrequency targets than for high-frequency targets (i.e., ho- 

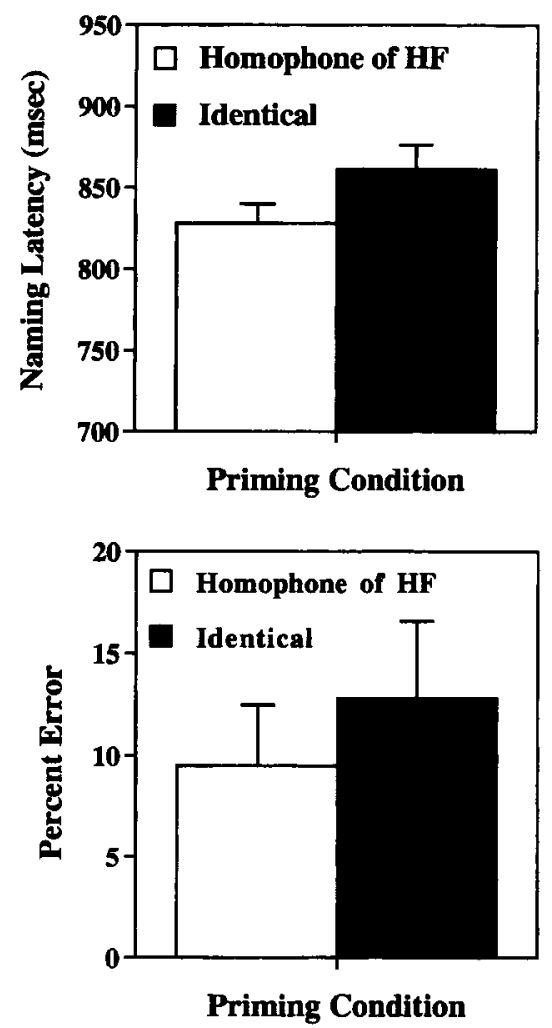

Figure 4. Mean naming latencies (in milliseconds) and percent errors in Experiment 3 (picture naming) as a function of type of prime-target relation (homophone of higher frequency vs. identical). Vertical bars represent standard errors. HF, higher frequency.

mophone priming and frequency interact). In Experiment 3 , we obtained a counterintuitive result: Using picture targets with low-frequency names, priming was stronger from written homophones with higher frequency names than from identical primes.

\section{Locus of the Priming Effect}

In the present experiments, we used homophone primes in order to reduce the possibility that the priming effect is semantic in nature (see Figure 1). Since strong homophone priming occurred, we concluded that priming is not semantic in nature. Alternative possibilities remain: (1) The priming may affect the perception of the picture itself, or (2) it may directly activate the phonological representation of the picture name (or the retrieval of the name of the picture), or (3) it may affect the articulation of the name of the picture. We wish to argue for the second possibility. In our previous experiments (Ferrand, 1995; Ferrand et al., 1994), we obtained priming with pseudohomophone primes (e.g., roze-ROSE). Our explanation was that the pseudohomophone prime is converted into a phonological representation that then activates the phonological lexical representation for ROSE, so that when the picture occurs, its name is already active. In the present experiments, we obtained priming for homophone pairs such as rows-
ROSE. We may assume that exactly the same sequence of processes takes place: The homophone prime is converted into a phonological representation that activates the phonological lexical representation for ROSE. Priming reflects shared whole-word phonology between primes and targets. Another alternative (the third account above) suggests that the priming effect reflects speeded articulation of the name of the picture. However, there is evidence for activation of a name representation, rather than articulation per se, since (1) equivalent amounts of facilitation occurred following covert and overt naming practice (Brown et al., 1991; Johnson et al., 1996), and (2) phonological priming occurs in word reading tasks that do not involve overt production (Ferrand et al., 1994; Ferrand et al., 1995).

The important difference between priming from a homophone (rows-ROSE) and a pseudohomophone (roze-ROSE) is in the reduced likelihood that the semantic system serves as a locus of the effect. A pseudohomophone (roze) does not visually access semantic information, whereas a word (rows) does, but in the latter case the semantic information differs from that accessed by the target. It could be that a pseudohomophone prime (roze) activates the semantic representation of the corresponding picture name ROSE, enabling both semantic and phonological information to contribute to the priming effect (see Wheeldon \& Monsell, 1992, for instance). It might also be argued that written homophones can access the semantics of the alternative meaning of the spoken word (e.g., rows-ROSE), especially when the words are briefly presented and pattern masked (e.g., Lesch \& Pollatsek, 1993; Lukatela \& Turvey, 1994; see also Van Orden, 1987). However, unlike with pseudohomophones, there would then be competing semantic representations present, which should reduce priming. Also, the homophone primes here were higher in frequency than the targets, making it more likely that semantic representations of primes are activated even from phonology. Note too that priming from homophones (when competing semantic representations may be activated) was as large as repetition priming (when single semantic representations should be activated) in the present paradigm (Experiments 1 and 2).

\section{Frequency Effects in Picture Naming}

In a seminal study, Balota and Chumbley (1985) demonstrated that word frequency can modulate the speed of articulatory programming and articulation to some extent in word naming. According to these authors, high-frequency articulatory-motor programs for words may be compiled and executed faster than low-frequency ones. The main support for this view comes from the existence of a frequency effect in a delayed naming task. In a control experiment, we ruled out the possibility that the present frequency effect observed in picture naming reflects differences in the speed of initiating articulation. Indeed, although a robust frequency effect was observed in an immediate picture naming task (Experiments 1 and 2), this effect vanished in delayed picture naming. ${ }^{3}$ Our results suggest that the frequency effect in picture naming affects lexical ac- 
cess rather than production components (see Jescheniak \& Levelt, 1994, and Johnson et al., 1996, for the same conclusion). Furthermore, Wingfield (1968) and Jescheniak and Levelt showed that the frequency effect was not due to the time needed to recognize the object, but reflects name retrieval operations. Whether this effect is due solely to the frequency of occurrence of an object's name or to a correlated variable such as the familiarity of the name or the age at which the name was acquired is still under debate (Brysbaert, 1996; Morrison et al., 1992).

\section{Priming and Name Frequency}

In Experiment 1, repetition priming combined additively with picture name frequency, a result that replicates prior studies that have assessed masked repetition priming and frequency (Ferrand, 1996; Ferrand et al., 1994; Forster \& Davis, 1984; Humphreys, Besner, \& Quinlan, 1988; Segui \& Grainger, 1990; Sereno, 1991). However, in Experiment 2, with homophone primes, priming effects were larger on targets with low- relative to high-frequency names. The results of Experiment 3 confirm that more frequent homophone primes facilitate target processing compared with identical primes. We suggest that this last surprising result came about because the homophone primes were more frequent than the low-frequency target names, and so produced strong activation of the phonological lexicon. This strong activation is consistent with an interactive activation approach to picture naming (Ferrand et al., 1994; Humphreys, Lamote, \& Lloyd-Jones, 1995; Humphreys, Lloyd-Jones, \& Fias, 1995; Humphreys, Riddoch, \& Quinlan, 1988; Vitkovitch et al., 1993). We suggest that highfrequency primes activate their phonological representations to a greater extent than low-frequency primes, under masked priming conditions. The consequence of this is that the naming of low-frequency picture targets is facilitated more by high-frequency homophone primes than even by identical words (which, by definition, will be of lower frequency). This can also explain the interaction between frequency and homophone priming in Experiment 2 . The primes of low-frequency homophone targets are more frequent than the targets themselves, whereas those of high-frequency homophone targets are less frequent. Since the magnitude of phonological priming is determined by the frequency of the prime, then, priming is largest with high-frequency primes/low-frequency targets. However, if priming is a function of the frequency of the prime, why does frequency combine additively with repetition priming (Experiment 1)? Here, increased activation from high-frequency primes may be balanced against the "space" for priming high-frequency targets. For example, high-frequency targets may have residual activation levels closer to threshold, and so show a smaller change when primed relative to low-frequency targets whose activation levels show a differential increase from priming. The net result, of having increased activation from primes but activation levels close to threshold, may be to generate equal repetition effects for high- and low-frequency targets. According to the activation model of picture nam- ing developed by Ferrand et al. (1994), these priming effects observed in picture naming result from the prime stimulus preactivating in memory the phonological representation corresponding to the picture name. Such a wholeword phonological representation is then used to generate the name of the following picture target, and the rapidity with which an articulatory output is constructed is assumed to depend on the activation level of this phonological representation. The higher the activation level of the phonological representation, the faster the articulatory output is constructed.

\section{REFERENCES}

Bajo, M. T., \& Canas, J. J. (1989). Phonetic and semantic activation during picture and word naming. Acta Psychologica, 72, 105-115.

Balota, D. A., \& Chumbley, J. I. (1985). The locus of word-frequency effects in the pronunciation task: Lexical access and/or production? Journal of Memory \& Language, 24, 89-106.

BAVELIER, D. (1994). Repetition blindness between visually different items: The case of pictures and words. Cognition, 51, 199-236.

Berent, I., \& Perfetti, C. A. (1995). A Rose is a Reez: The two-cycles model of phonology assembly in reading English. Psychological Review, 102, 146-184.

Brown, A. S., Neblett, D. R., Jones, T. C., \& Mitchell, D. B. (1991). Transfer of processing in repetition priming: Some inappropriate findings. Journal of Experimental Psychology: Learning, Memory, \& Cognition, 17, 514-525.

BRYSBAERT, M. (1996). Word frequency affects naming latency in Dutch when age of acquisition is controlled. European Journal of Cognitive Psychology, 8, 185-193.

Collins, A. F., \& ElLIs, A. W. (1992). Phonological priming of lexical retrieval in speech production. British Journal of Psychology, 83, 375-388.

DELL, G. S. (1988). The retrieval of phonological forms in production: Tests of predictions from a connectionist model. Journal of Memory \& Language, 27, 124-142.

Durso, F. T., \& Johnson, M. K. (1979). Facilitation in naming and categorizing repeated pictures and words. Journal of Experimental Psychology: Human Learning \& Memory, 5, 449-459.

FerRaND, L. (1995). Repeated prime-target presentations do not eliminate repetition and phonological priming in naming digits. Acta Psychologica, 89, 217-227.

FERRAND, L. (1996). The masked repetition priming effect dissipates when increasing the interstimulus interval: Evidence from word naming. Acta Psychologica, 91, 15-25.

Ferrand, L. (1997). Picture naming: Theories and data. L'Année Psychologique, 97, 112-146.

Ferrand, L., \& Grainger, J. (1992). Phonology and orthography in visual word recognition: Evidence from masked nonword priming. Quarterly Journal of Experimental Psychology, 45A, 353-372.

FERRAND, L., \& GRAINGER, J. (1993). The time course of orthographic and phonological code activation in the early phases of visual word recognition. Bulletin of the Psychonomic Society, 31, 119-122.

FERRAND, L., \& GRAINGER, J. (1994). Effects of orthography are independent of phonology in masked form priming. Quarterly Journal of Experimental Psychology, 47A, 365-382.

FerRaND, L., \& GRaINGER, J. (1996). List context effects on masked phonological priming in the lexical decision task. Psychonomic Bulletin \& Review, 3, 515-519.

Ferrand, L., Grainger, J., \& Segui, J. (1994). A study of masked form priming in picture and word naming. Memory \& Cognition, 22, 431-441.

FERRAND, L., SEgui, J., \& Grainger, J. (1995). Amorçage phonologique masqué et dénomination [Masked phonological priming and picture naming]. L'Année Psychologique, 95, 645-659.

FerRand, L., Segui, J., \& Grainger, J. (1996). Masked priming of word and picture naming: The role of syllabic units. Journal of Memory \& Language, 35, 708-723.

Forster, K. I., \& DAVIS, C. (1984). Repetition priming and frequency 
attenuation in lexical access. Journal of Experimental Psychology: Learning, Memory, \& Cognition, 10, 680-698.

Forster, K. I., \& DAVIS, C. (1991). The density constraint on formpriming in the naming task: Interference effects from a masked prime. Journal of Memory \& Language, 30, 1-25.

FrANCIS, W. N., \& KuČERA, H. (1982). Frequency analysis of English usage: Lexicon and grammar. Boston: Houghton Mifflin.

GlaSer, W. R. (1992). Picture naming. Cognition, 42, 61-105.

Grainger, J., \& FerRand, L. (1994). Phonology and orthography in visual word recognition: Effects of masked homophone primes. Journal of Memory \& Language, 33, 218-233.

GraingER, J., \& FerRAND, L. (1996). Masked orthographic and phonological priming in visual word recognition and naming: Cross-task comparisons. Journal of Memory \& Language, 35, 623-647.

Humphreys, G. W., Besner, D., \& Quinlan, P. T. (1988). Event perception and the word repetition effect. Journal of Experimental Psychology: General, 117, 51-67.

Humphreys, G. W., LAMOTE, C., \& Lloyd-Jones, T. J. (1995). An interactive activation approach to object processing: Effects of structural similarity, name frequency and task in normality and pathology. Memory, 3, 535-586.

Humphreys, G. W., Lloyd-Jones, T. J., \& Fias, W. (1995). Semantic interference on naming using a post-cue procedure: Tapping the links between semantics and phonology with pictures and words. Journal of Experimental Psychology: Learning, Memory, \& Cognition, 21, 961-980.

HumphreYs, G. W., RidDOCH, M. J., \& QuinLAN, P. T. (1988). Cascade processes in picture identification. Cognitive Neuropsychology, $\mathbf{5}$, 67-103.

HutTENLOCHER, J., \& KUBICEK, L. F. (1983). The source of relatedness effects on naming latency. Journal of Experimental Psychology: Learning, Memory, \& Cognition, 9, 486-496.

JaCobs, A. M., Grainger, J., \& Ferrand, L. (1995). The incremental priming technique: A method for determining within-condition priming effects. Perception \& Psychophysics, 57, 1101-1110.

JesCHENIAK, J. D., \& LEVELT, W. J. M. (1994). Word frequency effects in speech production: Retrieval of syntactic information and of phonological form. Journal of Experimental Psychology: Learning, Memory, \& Cognition, 20, 824-843.

Johnson, C. J., Paivio, A., \& Clark, J. M. (1996). Cognitive components of picture naming. Psychological Bulletin, 120, 113-139.

Lesch, M. F., \& PollatseK, A. (1993). Automatic access of semantic information by phonological codes in visual word recognition. Journal of Experimental Psychology: Learning, Memory, \& Cognition, 14, 618-626.

Lloyd-Jones, T. J., \& Humphreys, G. W. (1995, July). Semantic and phonological interference effects on picture naming using a post-cue procedure: Studying the time course of object name retrieval. Paper presented at the European Summer School on Aspects of Speech Production, University of Birmingham, U.K.

Lukatela, G., \& Turvey, M. T. (1994). Visual access is initially phonological: 1. Evidence from associate priming by words, homophones, and pseudohomophones. Journal of Experimental Psychology: General, 123, 107-108.

LUPKER, S. J. (1982). The role of phonetic and orthographic similarity in picture-word interference. Canadian Journal of Psychology, 36, 349-367.

LuPKer, S. J., \& Williams, B. A. (1989). Rhyme priming of pictures and words: A lexical activation account. Journal of Experimental Psychology: Learning, Memory, \& Cognition, 15, 1033-1046.

MarmuREK, H. H. C. (1994). Linguistic processing of words and pictures. American Journal of Psychology, 107, 519-536.

MCCANN, R. S., \& BESNER, D. (1987). Reading pseudohomophones: Implications for models of pronunciation assembly and the locus of word-frequency effects in naming. Journal of Experimental Psychology: Human Perception \& Performance, 13, 14-24.

McClelland, J. L., \& Rumelhart, D. E. (1981). An interactive activation model of context effects in letter perception: Part 1 . An account of basic findings. Psychological Review, 88, 375-405.

McEvoy, C. L. (1988). Automatic and strategic processes in picture naming. Journal of Experimental Psychology: Learning, Memory, \& Cognition, 14, 618-626.
Meyer, A. S., \& Schriefers, H. (1991). Phonological facilitation in picture-word interference experiments: Effects of stimulus onset asynchrony and types of interfering stimuli. Journal of Experimental Psychology: Learning, Memory, \& Cognition, 17, 1146-1160.

Morrison, C. M., Ellis, A. W., \& Quinlan, P. T. (1992). Age of acquisition, not word frequency, affects object naming, not object recognition. Memory \& Cognition, 20, 705-714.

OLDFIELD, R. C., \& WINGFIELD, A. (1965). Response latencies in naming objects. Quarterly Journal of Experimental Psychology, 17, 273-281.

Perfetti, C. A., \& Bell, L. (1991). Phonemic activation during the first $40 \mathrm{~ms}$ of word identification: Evidence from backward masking and priming. Journal of Memory \& Language, 30, 473-485.

RAYNeR, K., \& Posnansky, C. (1978). Stages of processing in word identification. Journal of Experimental Psychology: General, 107, 64-80.

RidDOCH, M. J., \& HUMPHREYS, G. W. (1987). Picture naming. In G. W. Humphreys \& M. J. Riddoch (Eds.), Visual object processing: $A$ cognitive neuropsychological approach (pp. 107-144). London: Erlbaum.

SChriefers, H., Meyer, A. S., \& Levelt, W. J. M. (1990). Exploring the time course of lexical access in production: Picture-word interference studies. Journal of Memory \& Language, 29, 86-102.

Segui, J., \& Grainger, J. (1990). Priming word recognition with orthographic neighbors: Effects of relative prime-target frequency. Journal of Experimental Psychology: Human Perception \& Performance, 16, 65-76.

SERENO, J. A. (1991). Graphemic, associative, and syntactic priming effects at a brief stimulus onset asynchrony in lexical decision and naming. Journal of Experimental Psychology: Learning, Memory, \& Cognition, 17, 459-477.

SNODGRass, J. G., \& VANDERwarT, M. (1980). A standardized set of 260 pictures: Norms for name agreement. Journal of Experimental Psychology: Human Learning \& Memory, 6, 174-215.

Starreveld, P. A., \& La HeIJ, W. (1995). Semantic interference, orthographic facilitation, and their interaction in naming tasks. Journal of Experimental Psychology: Learning, Memory, \& Cognition, 21, 686-698.

Stemberger, J. P. (1985). An interactive activation model of language production. In A. W. Ellis (Ed.), Progress in the psychology of language (Vol. 1, pp. 143-186). Hillsdale, NJ: Erlbaum.

UNDERWOOD, G., \& BRIGGS, P. (1984). The development of word recognition processes. British Journal of Psychology, 73, 117-129.

VAN ORDEN, G. C. (1987). A Rows is a ROSE: Spelling, sound and reading. Memory \& Cognition, 15, 181-198.

VITKOVITCH, M., \& HUMPhreYs, G. W. (1991). Perseverant responding in speeded picture naming: It's in the links. Journal of Experimental Psychology: Learning. Memory, \& Cognition, 17, 664-680.

VitKovitch, M., HumPHREYs, G. W., \& LloYd-JoNES, T. J. (1993). On naming a giraffe a zebra: Picture naming errors across different object categories. Journal of Experimental Psychology: Learning, Memory, \& Cognition, 19, 243-259.

WHEELDON, L. R., \& MONSELL, S. (1992). The locus of repetition priming in spoken word production. Quarterly Journal of Experimental Psychology, 44A, 723-761.

WINGFIELD, A. (1968). Effects of frequency on identification and naming of objects. American Journal of Psychology, 81, 226-234.

XING, K., \& FORSTER, K. I. (1996). Masked phonological priming in picture naming: Lexical access or articulatory facilitation? Unpublished manuscript, University of Arizona, Department of Psychology.

ZiEgLER, J. C., \& JACOBS, A. M. (1995). Phonological information provides early sources of constraint in the processing of letter strings. Journal of Memory \& Language, 34, 567-593.

\section{NOTES}

1. In our earlier experiments (Ferrand, Grainger, \& Segui, 1994), we used stimuli in the unrelated conditions that shared the word onset with the corresponding targets. Following Forster and Davis (1991), we argued that this was necessary to rule out the possibility that differences between related and unrelated conditions were due to onset interference in the unrelated condition. In the present study, unrelated prime-target pairs did not share the onset. What motivated this change of baseline were new re- 
sults obtained by Grainger and Ferrand (1996). These authors showed that with shorter prime exposures (around $43 \mathrm{msec}$ ), there was no evidence for an onset interference effect. The inhibitory component of onset effects seems to arise when sufficient time is given for prime processing. Given that prime exposures were around $29 \mathrm{msec}$ in the present study, we did not expect an onset interference effect, so we did not control this factor.

2. The terms inhibition and facilitation are used here to refer to increases and decreases in response time and/or percent errors relative to an unrelated prime condition. However, see Jacobs, Grainger, and Ferrand (1995) for a discussion of alternative ways of interpreting these concepts.

3. In order to test the hypothesis that the frequency effect observed in our picture naming experiments was indeed a purely lexical effect not contaminated by articulation, we conducted a control study involving a delayed picture naming task. In this task, 20 subjects saw a picture and prepared its pronunciation. After a delay, a cue $(* * * * * *)$ signaled them to initiate the vocal response. It was assumed that if the delay was long enough, the picture would have been recognized and the articulatory motor program assembled and stored in a buffer. On presentation of the cue, the subject would retrieve and execute this motor program. Any remaining effect of frequency, then, would have to be attributed to the stage of response execution (Jescheniak \& Levelt, 1994). To ensure that our subjects fully prepared the utterance at the cue onset, we used a delay of $2,000 \mathrm{msec}$ (see Marmurek, 1994). The picture targets used were exactly the same as those in Experiment 1. The results obtained were $555 \mathrm{msec}$ for high-frequency targets and $556 \mathrm{msec}$ for low-frequency targets. The 1-msec advantage was not significant (all $F \mathrm{~s}<1$, and all $p \mathrm{~s}>.50$ ).

\section{APPENDIX A}

Stimuli Used in Experiment 1 With Their Corresponding Frequencies (From Francis \& Kucera, 1982)

\begin{tabular}{|c|c|c|c|c|c|}
\hline \multicolumn{2}{|c|}{ Target } & \multicolumn{2}{|c|}{ Identical Prime } & \multicolumn{2}{|c|}{ Unrelated Prime } \\
\hline \multicolumn{6}{|c|}{ High Frequency } \\
\hline BALL & 110 & BALL & 110 & CLAP & 9 \\
\hline BEAR & 57 & BEAR & 57 & FLED & 1 \\
\hline Bow & 15 & BOW & 15 & TONER & 3 \\
\hline BOWL & 23 & BOWL & 23 & TWIG & 1 \\
\hline BREAD & 41 & BREAD & 41 & PALS & 1 \\
\hline DEER & 13 & DEER & 13 & FOLK & 53 \\
\hline EYE & 122 & EYE & 122 & KIT & 3 \\
\hline GATE & 37 & GATE & 37 & SLUM & 8 \\
\hline HAIR & 148 & HAIR & 148 & LOWN & 1 \\
\hline HEART & 173 & HEART & 173 & PUMP & 15 \\
\hline HORSE & 117 & HORSE & 117 & CHILLY & 5 \\
\hline KEY & 88 & KEY & 88 & BASK & 3 \\
\hline NOSE & 60 & NOSE & 60 & VICAR & 4 \\
\hline PLANE & 114 & PLANE & 114 & DOUBT & 28 \\
\hline ROSE & 86 & ROSE & 86 & TAXI & 2 \\
\hline SEAL & 17 & SEAL & 17 & RUNE & 1 \\
\hline SHOE & 14 & SHOE & 14 & TINT & 1 \\
\hline SUN & 112 & SUN & 112 & HIT & 126 \\
\hline \multicolumn{6}{|c|}{ Low Frequency } \\
\hline BUOY & 2 & BUOY & 2 & CAR & 393 \\
\hline CARROT & 1 & CARROT & 1 & RUBY & 1 \\
\hline CORD & 6 & CORD & 6 & SWELL & 20 \\
\hline CYMBAL & 0 & CYMBAL & 0 & LAWYER & 69 \\
\hline FIR & 2 & FIR & 2 & EGO & 14 \\
\hline GORILLA & 0 & GORILLA & 0 & MEDICINE & 35 \\
\hline HEEL & 9 & HEEL & 9 & RUSH & 17 \\
\hline HANGER & 0 & HANGER & 0 & MOTTLE & 3 \\
\hline MAIZE & 0 & MAIZE & 0 & SLUG & 9 \\
\hline MEDAL & 7 & MEDAL & 7 & PAJAMA & 4 \\
\hline OAR & 0 & OAR & 0 & LAX & 3 \\
\hline PAIL & 4 & PAIL & 4 & BUSY & 57 \\
\hline PEAR & 6 & PEAR & 6 & TEXT & 64 \\
\hline RAZOR & 5 & RAZOR & 5 & TEDIUM & 1 \\
\hline SLEIGH & 0 & SLEIGH & 0 & GALE & 1 \\
\hline SWORD & 7 & SWORD & 7 & RUNNER & 6 \\
\hline TOAD & 4 & TOAD & 4 & PLASM & 1 \\
\hline WHALE & 0 & WHALE & 0 & STUB & 5 \\
\hline
\end{tabular}




\section{APPENDIX B}

Stimuli Used in Experiment 2 and in Experiment 3

(Only Low-Frequency Targets) With Their Corresponding

Frequencies (From Francis \& Kučera, 1982)

\begin{tabular}{lrlrlr}
\hline \multicolumn{1}{r}{ Target } & & \multicolumn{2}{c}{ Homophone Prime } & \multicolumn{2}{c}{ Unrelated Prime } \\
\hline High Frequency & & & & & \\
BALL & 110 & BAWL & 3 & CLAP & 9 \\
BEAR & 57 & BARE & 1 & FLED & 1 \\
BOW & 15 & BOUGH & 6 & TONER & 3 \\
BOWL & 23 & BOLL & 1 & TWIG & 1 \\
BREAD & 41 & BRED & 1 & PALS & 1 \\
DEER & 13 & DEAR & 45 & FOLK & 53 \\
EYE & 122 & AYE & 1 & KIT & 3 \\
GATE & 37 & GAIT & 8 & SLUM & 8 \\
HAIR & 148 & HARE & 1 & LOWN & 1 \\
HEART & 173 & HART & 13 & PUMP & 15 \\
HORSE & 117 & HOARSE & 5 & CHILLY & 5 \\
KEY & 88 & QUAY & 1 & BASK & 3 \\
NOSE & 60 & KNOWS & 1 & VICAR & 4 \\
PLANE & 114 & PLAIN & 21 & DOUBT & 28 \\
ROSE & 86 & ROWS & 1 & TAXI & 2 \\
SEAL & 17 & SEEL & 1 & RUNE & 1 \\
SHOE & 14 & SHOO & 1 & TINT & 1 \\
SUN & 112 & SON & 202 & HIT & 126 \\
LOW Frequency & & & & & \\
BUOY & 2 & BOY & 409 & CAR & 393 \\
CARROT & 1 & KARAT & 1 & RUBY & 1 \\
CORD & 6 & CHORD & 13 & SWELL & 20 \\
CYMBAL & 0 & SYMBOL & 90 & LAWYER & 69 \\
FIR & 2 & FUR & 17 & EGO & 14 \\
GORILLA & 0 & GUERRILLA & 30 & MEDICINE & 35 \\
HEEL & 9 & HEAL & 11 & RUSH & 17 \\
HANGER & 0 & HANGAR & 2 & MOTTLE & 3 \\
MAIZE & 0 & MAZE & 6 & SLUG & 9 \\
MEDAL & 7 & MEDDLE & 4 & PAJAMA & 4 \\
OAR & 0 & ORE & 3 & LAX & 3 \\
PAIL & 4 & PALE & 57 & BUSY & 57 \\
PEAR & 6 & PAIR & 64 & TEXT & 64 \\
RAZOR & 5 & RAISER & 1 & TEDIUM & 1 \\
SLEIGH & 0 & SLAY & 1 & GALE & 1 \\
SWORD & SOARED & 3 & RUNNER & 6 \\
TOAD & TOWED & 1 & PLASM & 1 \\
WHALE & & & 5 & STUB & 5 \\
\hline & & & & & \\
\hline
\end{tabular}

(Manuscript received October 16, 1995;

revision accepted for publication February 10, 1997.) 